\title{
DIFFERENTIAL 3D MUELLER-MATRIX MAPPING OF OPTICALLY ANISOTROPIC DEPOLARIZING BIOLOGICAL LAYERS
}

\author{
O.G. Ushenko ${ }^{1}$, M. Grytsyuk ${ }^{2}$, V.O.Ushenko ${ }^{1}$, G.B. Bodnar ${ }^{2}$, O. Vanchulyak ${ }^{2}$, I. Meglinskiy ${ }^{3}$ \\ 1 Chernivtsi National University, 2 Kotsiubynskyi St., Chernivtsi, Ukraine, 58012 \\ 2 Bukovinian State Medical University, 3 Theatral Sq., Chernivtsi, Ukraine, 58000 \\ ${ }^{\mathrm{c}}$ University of Oulu, P.O. Box 4500, Oulu, Finland
}

\begin{abstract}
The paper consists of two parts. The first part is devoted to the short theoretical basics of the method of differential Mueller-matrix description of properties of partially depolarizing layers. It was provided the experimentally measured maps of differential matrix of the 2nd order of polycrystalline structure of the histological section of rectum wall tissue. It was defined the values of statistical moments of the1st-4th orders, which characterize the distribution of matrix elements. In the second part of the paper it was provided the data of statistic analysis of birefringence and dichroism of the histological sections of connecting component of vagina wall tissue (normal and with prolapse). It were defined the objective criteria of differential diagnostics of pathologies of vagina wall.
\end{abstract}

Keywords: Mueller matrix, biological tissue, diagnostic, correlometry.

\section{THEORETICAL BASICS AND EXPERIMENTAL REALIZATION OF DIFFERENTIAL MUELLER-MATRIX MAPPING OF BIOLOGICAL LAYERS}

\subsection{Brief theory of the method}

The theoretical basis of Mueller matrix approach ${ }^{1-3}$ to description of the interaction of optical radiation with multiple scattering layers is shown in a series of publications ${ }^{4-12}$. It was shown that depolarization properties of diffusive layer with Mueller matrix $\{M\}$ are described by means of differential matrix of the 2nd order $\left\{\Delta m^{2}\right\}$

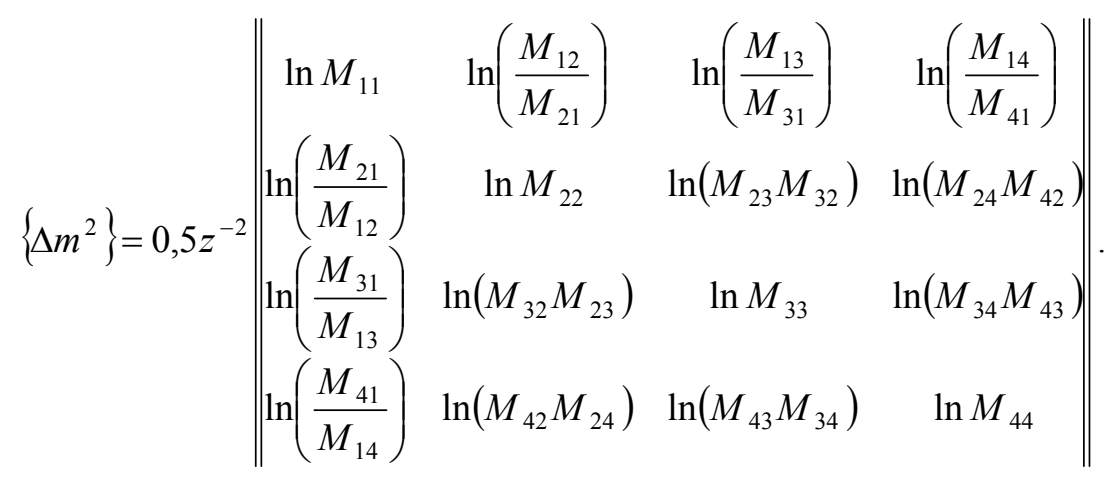

Physically, matrix operator (1) has the meaning of fluctuations $\left(\bar{\sigma}_{i}^{2}\right)$ of polarization properties

Thirteenth International Conference on Correlation Optics, edited by

Oleg V. Angelsky, Proc. of SPIE Vol. 10612, 106121I · C) 2018 SPIE

CCC code: $0277-786 X / 18 / \$ 18 \cdot$ doi: $10.1117 / 12.2305329$ 


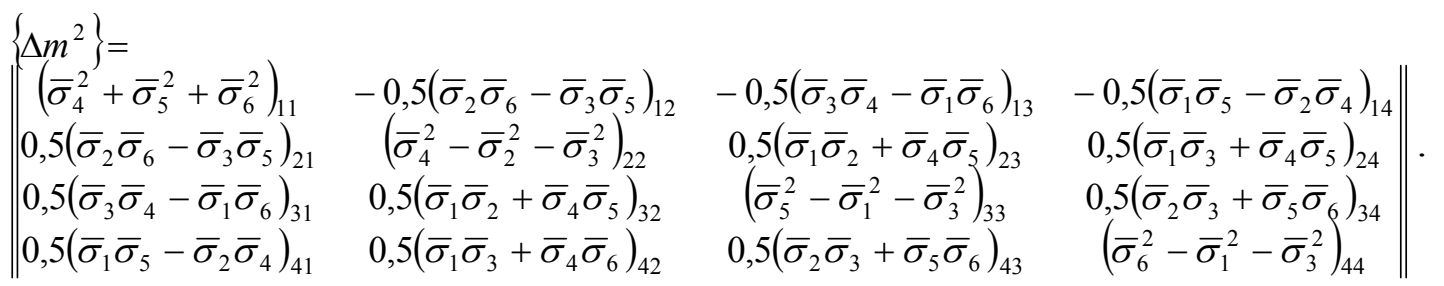

Here

$$
\sigma_{i}=\left(\begin{array}{l}
\sigma_{1}=\sqrt{D_{L D}} \\
\sigma_{2}=\sqrt{D_{C D}} \\
\sigma_{3}=\sqrt{D_{L D^{\prime}}} \\
\sigma_{4}=\sqrt{D_{L B}} \\
\sigma_{5}=\sqrt{D_{C B}} \\
\sigma_{6}=\sqrt{D_{L B^{\prime}}}
\end{array}\right),
$$

where

- $\quad L D$ and $L B$ - linear dichroism and birefringence for the direction of the optical axis $\gamma=0^{0}$;

- $L D^{\prime}$ and $L B^{\prime}$ - linear dichroism and birefringence for the direction of the optical axis $\gamma=45^{\circ}$;

- $\quad C D$ and $C B$ - circular dichroism and birefringence;

- $\quad M_{i k}$ - Mueller-matrix elements ${ }^{13-22}$;

Such a parameters are in particular investigated for optically thin (non-depolarizing) layers of the histological sections of biological tissues and films of biological liquids ${ }^{23-39}$. For depolarizing layers such data is not obtained.

Thus, the use of ideology differential analysis of Mueller matrix mapping data allowed us to obtain a set of algorithms of polarization reconstruction of average values of флуктуаций phase and amplitude anisotropy parameters of polycrystalline component of biological layer.

The analysis of expressions (2)-(3) reveals the following physical content of the partial elements of the depolarization component of the Mueller matrix of the optically thick biological layer with fluctuations of the linear and circular birefringence and dichroism parameters. The diagonal elements $\left\{\Delta m^{2}\right\}_{i i}$ are determined by combinations of dispersion $D_{i}$ of the parameters fluctuations of various mechanisms of phase and amplitude anisotropy.

\subsection{Experimental results of the method differential mapping}

We obtain an expression for calculating elements of differential matrix of the 2 nd order

$$
\begin{aligned}
& \left\{\Delta m^{2}\right\}=0,5 z^{-2} \times \\
& \ln 0.5\left(V_{1}^{0}+V_{1}^{90}\right) \quad \ln \left(\frac{\left(V_{1}^{0}-V_{1}^{90}\right)}{\left.V_{2}^{0}+V_{2}^{90}\right)}\right) \quad \ln \left(\frac{V_{1}^{45}-0.5\left(V_{1}^{0}+V_{1}^{90}\right)}{0.5\left(V_{3}^{0}+V_{3}^{90}\right)}\right) \quad \ln \left(\frac{V_{1}^{\otimes}-0.5\left(V_{1}^{0}+V_{1}^{90}\right)}{0.5\left(V_{4}^{0}+V_{4}^{90}\right)}\right) \\
& \left.\ln \left(\frac{\left.V_{2}^{0}+V_{2}^{90}\right)}{\left(V_{1}^{0}-V_{1}^{90}\right)}\right) \quad \ln 0.5\left(V_{2}^{0}-V_{2}^{90}\right) \quad \ln \left(\left(V_{2}^{45}-0.5\left(V_{2}^{0}+V_{2}^{90}\right)\right) 0.5\left(V_{3}^{0}-V_{3}^{90}\right)\right) \ln 0.5\left(V_{4}^{0}-V_{4}^{90}\right)\left(V_{2}^{\otimes}-0.5\left(V_{2}^{0}+V_{2}^{90}\right)\right)\right) \\
& \times\left(\operatorname { l n } ( \frac { 0 . 5 ( V _ { 3 } ^ { 0 } + V _ { 3 } ^ { 9 0 } ) } { V _ { 1 } ^ { 4 5 } - 0 . 5 ( V _ { 1 } ^ { 0 } + V _ { 1 } ^ { 9 0 } ) } ) \operatorname { l n } \left(0.5\left(V_{3}^{0}-V_{3}^{90}\right)\left(V_{2}^{45}-0.5\left(V_{2}^{0}+V_{2}^{90}\right)\right) \quad \ln \left(V_{3}^{45}-0.5\left(V_{3}^{0}+V_{3}^{90}\right)\right) \quad \ln 0.5\left(V_{3}^{\otimes}-0.5\left(V_{3}^{0}+V_{3}^{90}\right)\left(V_{4}^{0}-V_{4}^{90}\right)\right)\right.\right. \\
& \left.\ln \left(\frac{0.5\left(V_{4}^{0}+V_{4}^{90}\right)}{V_{1}^{\otimes}-0.5\left(V_{1}^{0}+V_{1}^{90}\right)}\right) \ln 0.5\left(V_{4}^{0}-V_{4}^{90}\right)\left(V_{2}^{\otimes}-0.5\left(V_{2}^{0}+V_{2}^{90}\right)\right)\right) \ln 0.5\left(V_{3}^{\otimes}-0.5\left(V_{3}^{0}+V_{3}^{90}\right)\left(V_{4}^{0}-V_{4}^{90}\right)\right) \quad \ln \left(V_{4}^{\otimes}-0.5\left(V_{4}^{0}+V_{4}^{90}\right)\right)
\end{aligned}
$$


Here $V_{i=1 ; 2 ; 3 ; 4}^{0 ; 45, \otimes}$ - Stokes vectors of differently polarized beams ${ }^{1-3,13-16}$

The results of experimental approbation of the method of differential mapping of depolarizing component of polycrystalline structure of diffuse biological layer for optically thick layer of rectum ( $z=100 \mu m ; \tau=1,36 ; \Lambda=83 \%, z$ - geometrical thickness; $\tau$ - extinction coefficient; $\Lambda$ - depolarization degree) are illustrated by a series of dependencies (maps and histograms of $m_{i k}$ distributions), which are shown in Fig. 1 and Fig. 2
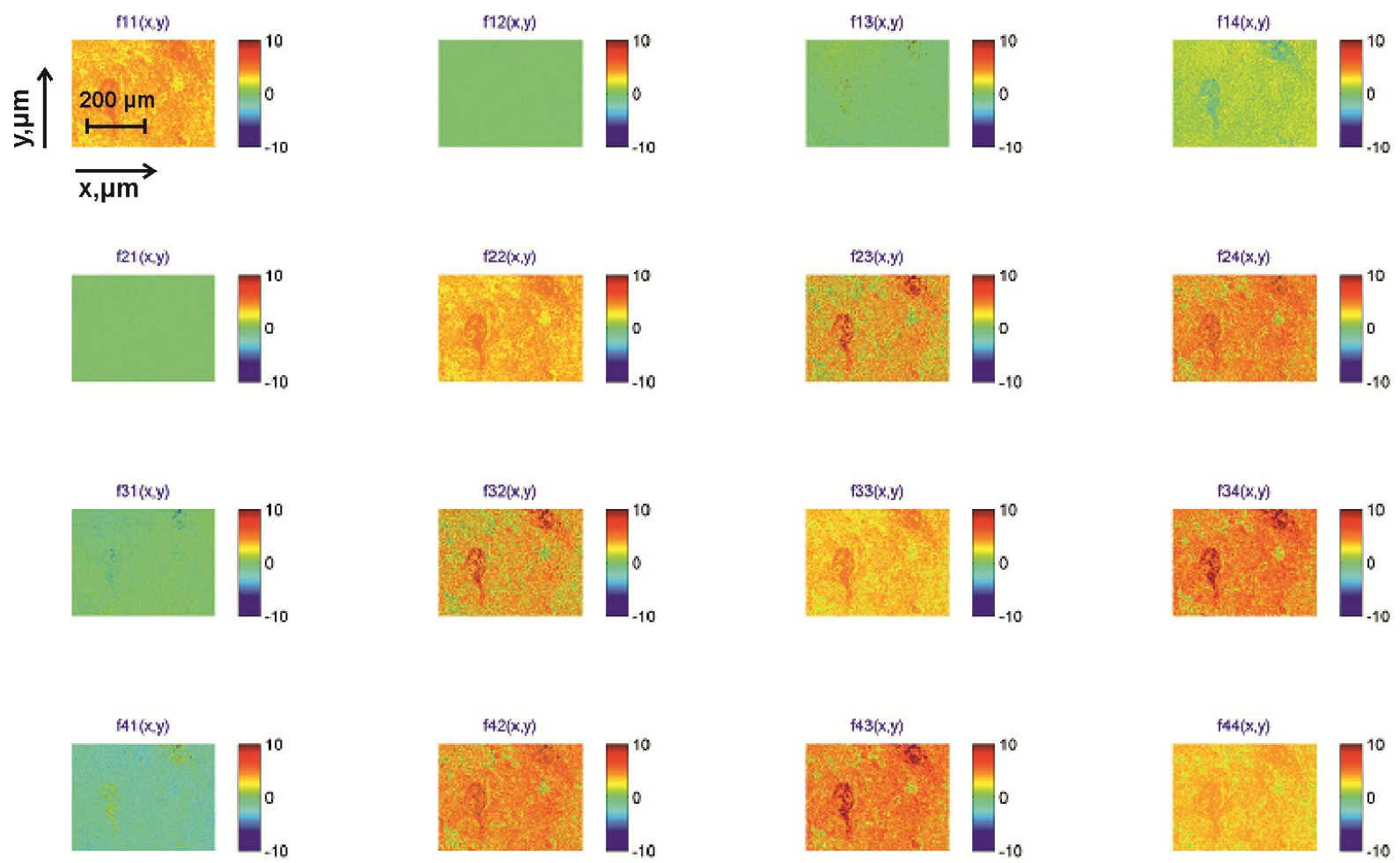

Fig. 1. Maps of elements of the 2st-order differential matrix of a histological section of rectum wall $(z=100 \mu m ; \tau=1,36 ; \Lambda=83 \%)$. 

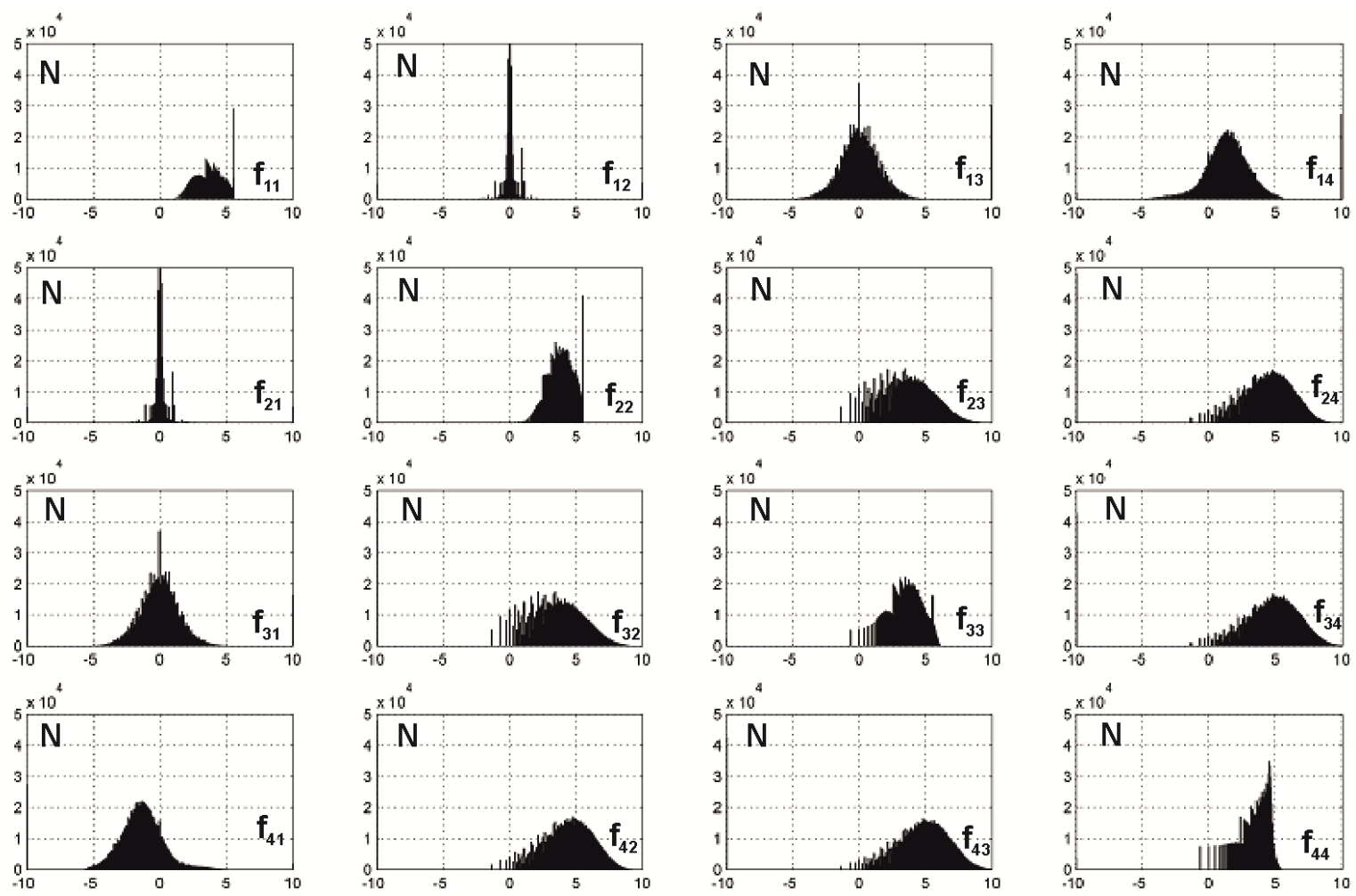

Fig. 2. Histograms of distribution of values of the 2st-order differential matrix elements of a histological section of rectum wall tissue ( $z=100 \mu m ; \tau=1,36 ; \Lambda=83 \%$ ).

Table 1 presents the results of statistic analysis (statistical moments of the 1 st- 4 th orders $Z_{i=1 ; 2 ; 3 ; 4}$ ) of coordinate distributions of the values of diagonal elements of differential Mueller matrix of the 2nd order.

Table 1. Statistical moments $Z_{i=1 ; 2 ; 3 ; 4}$ of the distributions of anisotropy parameters of depolarizing layer of rectum wall tissue

\begin{tabular}{|c|c|c|c|c|}
\hline$Z_{i=1 ; 2 ; 3 ; 4}$ & $\Delta m_{11}^{2}$ & $\Delta m_{22}^{2}$ & $\Delta m_{33}^{2}$ & $\Delta m_{44}^{2}$ \\
\hline$Z_{i=1}$ & 1,87 & 1,79 & 2,02 & 1,65 \\
\hline$Z_{i=2}$ & 1,37 & 1,55 & 1,29 & 1,42 \\
\hline$Z_{i=3}$ & 0,45 & 0,73 & 1,18 & 0,61 \\
\hline$Z_{i=4}$ & 0,78 & 1,27 & 1,85 & 0,94 \\
\hline
\end{tabular}

It was defined the individual sensitivity of the value of $Z_{i=3 ; 4}$ to the peculiarities of coordinate distributions of fluctuation of optical anisotropy parameters of partially depolarizing layer of rectum wall tissue.

Such a fact was chosen as the basic for applied biomedical usage of statistic analysis of coordinate distributions of fluctuation of both birefringence and dichroism values on diffusive layers of rectum wall tissue. 


\section{CLINICAL APPLICATION OF MUELLER-MATRIX MAPPING OF BIOLOGICAL LAYERS IN DIFFERENTIAL DIAGNOSTICS OF VAGINA WALL TISSUE WITH PROLAPSE}

\subsection{Objects of investigation}

It was investigated two groups of samples of biopsy of vagina wall tissue:

- healthy donors - control group 1 (30 samples);

- affected by prolapse - investigated group 2 (30 samples).

Histological sections were produced due to the standard technique on the freezing microtome.

\subsection{Experimental results}

The set of Figs. 3, 4 presents the results of Mueller-matrix mapping of the distributions of diagonal elements of differential matrix of the 2 nd order of diffusive layers of vagina wall tissue of donors (Fig.3) and with prolapse (Fig.4).
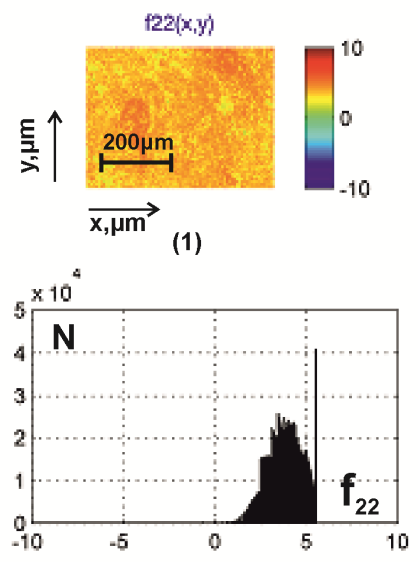

(4)
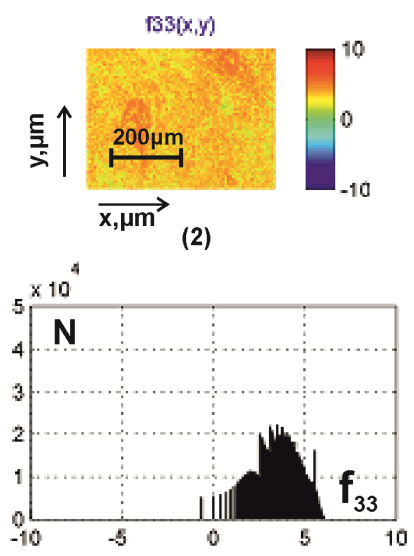

(5)
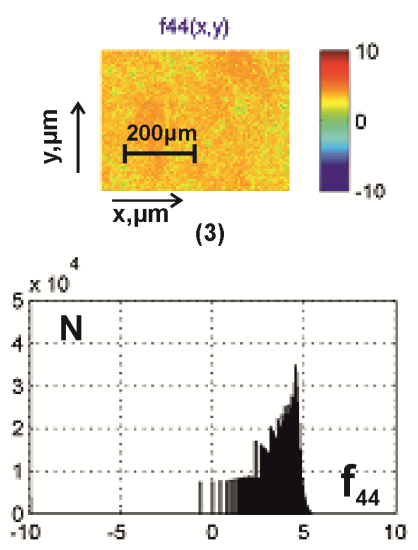

(6)

Fig. 3. Maps (upper line) and the histograms (bottom line) of the distribution values of diagonal elements $\Delta m_{i i}^{2}$ of the histological sections of biopsy of vagina wall of donors.

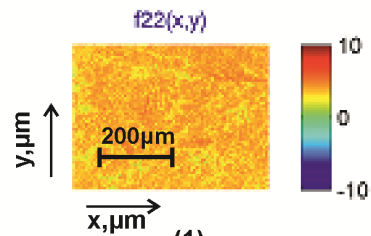

(1)

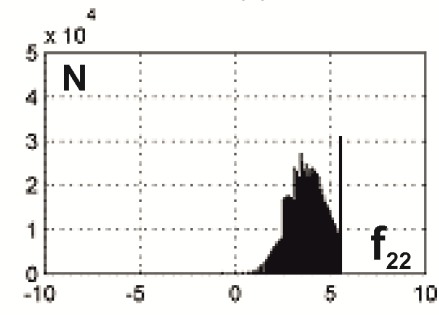

(4)

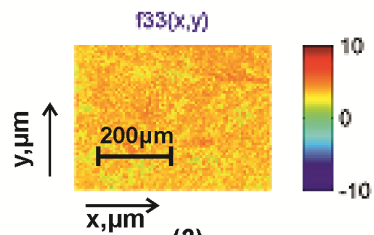

(2)

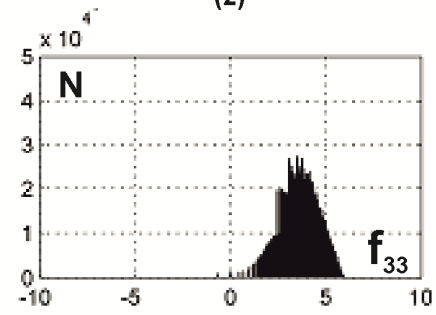

(5)

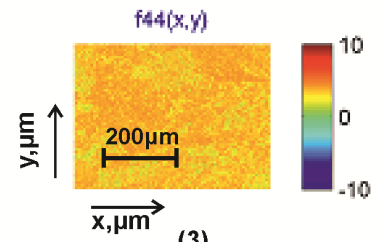

(3)

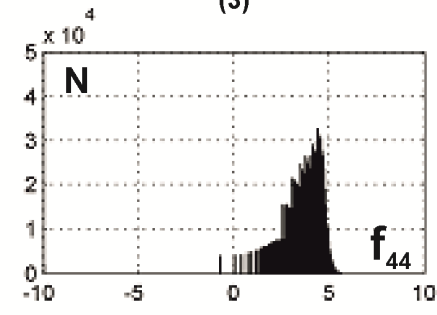

(6)

Fig. 4. Maps (upper line) and the histograms (bottom line) of the distribution values of diagonal elements $\Delta m_{i i}^{2}$ of the histological sections of biopsy of vagina wall of patients with prolapse. 
For the possible clinical application of the Mueller matrix mapping method for each group of samples the operating characteristics, typical for evidence-based medicine ${ }^{37-39}$ that determine the diagnostic power of the method are determined, namely - sensitivity $\left(S e=\frac{a}{a+b} 100 \%\right)$, specificity $\left(S p=\frac{c}{c+d} 100 \%\right)$ and balanced accuracy ( $A c=\frac{S e+S p}{2}$ ), where $a$ and $b$ - the number of correct and incorrect diagnoses within group $2 ; c$ and $d$ - the same within group 1 - Table 2 .

Table 2. Balanced accuracy of method of differential Mueller-matrix mapping

\begin{tabular}{|c|c|c|c|}
\hline$A c, \%$ & $\Delta m_{22}^{2}$ & $\Delta m_{33}^{2}$ & $\Delta m_{44}^{2}$ \\
\hline$Z_{i=1}$ & $61 \%$ & $67 \%$ & $64 \%$ \\
\hline$Z_{i=2}$ & $72 \%$ & $74 \%$ & $71 \%$ \\
\hline$Z_{i=3}$ & $88 \%$ & $92 \%$ & $93 \%$ \\
\hline$Z_{i=4}$ & $93 \%$ & $95 \%$ & $96 \%$ \\
\hline
\end{tabular}

It was reached a good $\left(A c\left(\Delta m_{22}^{2}\right)=88 \%-93 \%\right)$ and excellent $\left(A c\left(\Delta m_{33 ; 44}^{2}\right)=95 \%-96 \%\right)$ level of balanced accuracy of differential diagnostics of the biopsy samples of vagina wall tissue from donors and patients with prolapse.

\section{CONCLUSIONS}

Short theoretical basics of the method of differential Mueller-matrix mapping of the distribution of fluctuation of parameters of polycrystalline structure of depolarizing biological layers were provided. It was demonstrated the results of experimental approbation of such method and defined the parameters of differential Mueller matrix of the 2nd order of rectum wall tissue. The differential diagnostics of connecting component of vagina wall tissue was realized by means of statistic analysis of coordinate distribution fluctuation of the parameters of linear birefringence and dichroism of the diffusive samples of donors and patients with prolapse. It was reached a good and excellent levels of balanced accuracy of differential diagnostics of such samples.

\section{REFERENCES}

[1] Alexander G. Ushenko and Vasilii P. Pishak, "Laser Polarimetry of Biological Tissue: Principles and Applications", in Handbook of Coherent-Domain Optical Methods: Biomedical Diagnostics, Environmental and Material Science, vol. I, Valery V. Tuchin, Ed. Boston: Kluwer Academic Publishers, 2004, pp. 93-138.

[2] Angelsky, O.V., Bekshaev, A. Ya., Maksimyak, P. P., Maksimyak, A. P., Hanson, S.G. ,Zenkova, C. Yu., "Selfaction of continuous laser radiation and Pearcey diffraction in a water suspension with light-absorbing particles," Optics Express 22(3), 2267-2277 (2014).

[3] Y. A. Ushenko, T. M. Boychuk, V. T. Bachynsky, O. P. Mincer, "Diagnostics of Structure and Physiological State of Birefringent Biological Tissues: Statistical, Correlation and Topological Approaches" in Handbook of CoherentDomain Optical Methods, Springer Science+Business Media, p. 107, New York (2013).

[4] R. M. A. Azzam, Propagation of partially polarized light through anisotropic media with or without depolarization J. Opt. Soc. Am. 68 (1978) 1756-1767.

[5] R.C. Jones, A new calculus for the treatment of optical systems. VII properties of the N-matrices, J. Opt. Soc. Am. 38 (1948) 671-685.

[6] N. Ortega-Quijano, J.L. Arce-Diego, Mueller matrix differential decomposition, Opt. Letters 36 (2011) 1942-1944.

[7] N. Ortega-Quijano, J.L. Arce-Diego, Depolarizing differential Mueller matrices, Opt. Letters 36 (2011) 2429-2431. 
[8] V. Devlaminck, Physical model of differential Mueller matrix for depolarizing uniform media, J. Opt. Soc. Am. 30 (2013) 2196-2204.

[9] R. Ossikovski, V. Devlaminck, General criterion for the physical reliability of the differential Mueller matrix, Opt. Lett. 39 (2014) 1216-1219.

[10] V. Devlaminck, R. Ossikovski, Uniqueness of the differential Mueller matrix of uniform homogeneous media, Opt. Lett. 39 (2014) 3149-3152.

[11] R. Ossikovski, O. Arteaga, Statistical meaning of the differential Mueller matrix of depolarizing homogeneous media, Opt. Lett. 39 (2014) 4470-4473.

[12] R. Ossikovski, Differential matrix formalism for depolarizing anisotropic media, Opt. Letters. 36 (2011) 23302332.

[13] V.V. Tuchin, Tissue Optics: Light Scattering Methods and Instruments for Medical Diagnosis, second edition, SPIE Press, Bellingham, WA, PM 166, 2007.

[14] S. Bickel, W. M. Bailey, Stokes vectors, Mueller matrices, and polarization of scattered light, Am. J. Phys. 53 (1985) 468-478.

[15] X. Wang, G. Yao, L., H. Wang, Monte Carlo model and single-scattering approximation of polarized light propagation in turbid media containing glucose, Appl. Opt. 41 (2002) 792-801.

[16] X. Wang, L. - H. Wang, Propagation of polarized light in birefringent turbid media: a Monte Carlo study, J. Biomed. Opt. 7 (2002) 279-290.

[17] Angelsky, O. V., Bekshaev, A. Ya., Maksimyak, P. P., Maksimyak, A. P., Hanson, S. G., "Measurement of small light absorption in microparticles by means of optically induced rotation," Optics Express 23(6), 7152-7163 (2015).

[18] Polyanskii, V.K., Angelsky, O.V., Polyanskii, P.V., "Scattering-induced spectral changes as a singular optical effect," Optica Applicata 32 (4), 843-848 (2002).

[19] Angelsky, O.V., Besaha, R.N., Mokhun, A.I., Mokhun, I.I., Sopin, M.O., Soskin, M.S., "Singularities in vectoral fields," Proc. SPIE 3904, 40-54 (1999).

[20] Angelsky, O.V., Tomka, Y.Y., Ushenko, A.G., Ushenko, Y.G., Yermolenko, S.B., "2-D tomography of biotissue images in pre-clinic diagnostics of their pre-cancer states," Proc. SPIE 5972, 158-162 (2005).

[21] V. V. Tuchin, L. Wang, and D. A` . Zimnyakov, Optical Polarization in Biomedical Applications, New York, USA, 2006.

[22] R. A. Chipman, Polarimetry in Handbook of Optics: Vol. I- Geometrical and Physical Optics, Polarized Light, Components and Instruments, M. Bass, Ed., McGraw-Hill Professional, New York, 2010, pp. 22.1-22.37.

[23] Ushenko, A.G. "Polarization Correlometry of Angular Structure in the Microrelief Pattern of Rough Surfaces," Opt. Spectrosc. 92, 227-229 (2002) .

[24] Ushenko, A.G., Burkovets, D.N., Ushenko, Yu.A. "Polarization Phase Mapping and Reconstruction of Biological Tissue Architectonics during Diagnosis of Pathological Lesions," Optics and Spectroscopy (English translation of Optika i Spektroskopiya), 93 (3), 449-456 (2002).

[25] Yu.A. Ushenko, V.A. Ushenko, A.V. Dubolazov, V.O. Balanetskaya, N.I. Zabolotna, "Mueller-matrix diagnostics of optical properties of polycrystalline networks of human blood plasma," Optics and Spectroscopy 112, 884-892 (2012).

[26] V.A. Ushenko, O.V. Dubolazov, A.O. Karachevtsev, "Two wavelength Mueller matrix reconstruction of blood plasma films polycrystalline structure in diagnostics of breast cancer," Appl. Opt. 53, B128-B139 (2014).

[27] Y.A. Ushenko, G.D. Koval, A.G. Ushenko, O.V. Dubolazov, V.A. Ushenko, O.Yu. Novakovskaia, "Muellermatrix of laser-induced autofluorescence of polycrystalline films of dried peritoneal fluid in diagnostics of endometriosis," J. Biomed. Opt. 21(7), 071116 (2016).

[28] A.G. Ushenko, A.V. Dubolazov, V.A. Ushenko, O.Y. Novakovskaya, "Statistical analysis of polarization- 
inhomogeneous fourier spectra of laser radiation scattered by human skin in the tasks of differentiation of benign and malignant formations," J. Biomed. Opt. 21(7), 071110 (2016).

[29] V.P. Prysyazhnyuk, Yu.A. Ushenko, A.V. Dubolazov, A.G. Ushenko, V.A. Ushenko, "Polarization-dependent laser autofluorescence of the polycrystalline networks of blood plasma films in the task of liver pathology differentiation," Appl. Opt. 55, B126-B132 (2016).

[30] Angelsky, P. O., Ushenko, A. G., Dubolazov, A. V., Sidor, M. I., Bodnar, G. B., Koval, G., Trifonyuk, L., "The singular approach for processing polarization-inhomogeneous laser images of blood plasma layers," Journal of Optics, 15(4), 044030 (2013).

[31] Ushenko, O., Dubolazov, A., Balanets' ka, V., Karachevtsev, A., Sydor, M., "Wavelet analysis for polarization inhomogeneous laser images of blood plasma," Proc. SPIE. 8338, (2011).

[32] V. A. Ushenko, N. I. Zabolotna, S. V. Pavlov, D. M. Burcovets, O. Yu. Novakovska, "Mueller-matrices polarization selection of two-dimensional linear and circular birefringence images," Proc.SPIE 9066, (2013).

[33] V. A. Ushenko, A. V. Dubolazov, "Correlation and self similarity structure of polycrystalline network biological layers Mueller matrices images," Proc. SPIE 8856, (2013).

[34] Yu. A. Ushenko, V. A. Ushenko, A. V. Dubolazov, V. O. Balanetskaya, N. I. Zabolotna, "Mueller-matrix diagnostics of optical properties of polycrystalline networks of human blood plasma," Optics and Spectroscopy 112(6), 884-892 (2012).

[35] Yu. A. Ushenko, A. V. Dubolazov, V. O. Balanetskaya, A. O. Karachevtsev, V. A. Ushenko, "Wavelet-analysis of polarization maps of human blood plasma," Optics and Spectroscopy, 113(3), 332-343. (2012).

[36] V. O. Ushenko "Spatial-frequency polarization phasometry of biological polycrystalline networks" Optical Memory and Neural Networks, 22(1), 56-64 (2013).

[37] Brus, V.V., Pidkamin, L.I.,Arkhelyuk, A.D., "The effect of $\mathrm{CoO}$ impurity and substrate temperature on optical properties of TiO 2 thin films," Proc. SPIE 8338, 83381A ( 2011).

[38] Dobrovolsciy, Yu. G., G Perevertaylo, V. L., Shabashcevich, B. G., Pidkamin, L. J., "Clarifying coverages on the basis of tapes $\mathrm{SnO}$, SiO2, Si3N4 for photodiodes of ultraviolet and visible range," Proc. SPIE 7388, (2009).

[39] V. A. Ushenko, O. V. Dubolazov, A. O. Karachevtsev, "Two wavelength Mueller matrix reconstruction of blood plasma films polycrystalline structure in diagnostics of breast cancer," Applied Optics. 53(10), B128-B139 (2014).

[40] L. Cassidy, "Basic concepts of statistical analysis for surgical research," Journal of Surgical Research 128, 199-206 (2005).

[41] C. S. Davis, "Statistical methods of the analysis of repeated measurements," New York: Springer-Verlag, 744, (2002).

[42] A. Petrie, B. Sabin, "Medical Statistics at a Glance," Blackwell Publishing, 157, (2005). 